\title{
Resonant laser printing by Silicon crystallization and oxidation
}

Staif, Joseph; Bar-David, Jonathan; Engelberg, Jacob; Mazurski, Noa; Vakahi, Atzmon; Remennik, Sergei; Popov, Inna; Kristensen, Anders; Levy, Uriel

\section{Published in:}

Proceedings of the 2019 Conference on Lasers and Electro-Optics

Link to article, DOI:

10.1364/CLEO_AT.2019.JTu2A.109

Publication date:

2019

Document Version

Peer reviewed version

Link back to DTU Orbit

Citation (APA):

Staif, J., Bar-David, J., Engelberg, J., Mazurski, N., Vakahi, A., Remennik, S., Popov, I., Kristensen, A., \& Levy, U. (2019). Resonant laser printing by Silicon crystallization and oxidation. In Proceedings of the 2019 Conference on Lasers and Electro-Optics [8749418] IEEE. Conference on Lasers and Electro-optics https://doi.org/10.1364/CLEO_AT.2019.JTu2A.109

\section{General rights}

Copyright and moral rights for the publications made accessible in the public portal are retained by the authors and/or other copyright owners and it is a condition of accessing publications that users recognise and abide by the legal requirements associated with these rights.

- Users may download and print one copy of any publication from the public portal for the purpose of private study or research.

- You may not further distribute the material or use it for any profit-making activity or commercial gain

- You may freely distribute the URL identifying the publication in the public portal 


\title{
Resonant laser printing by Silicon crystallization and oxidation
}

\author{
Joseph Staif ${ }^{1,2}$, Jonathan Bar-David ${ }^{1,2}$, Jacob Engelberg ${ }^{1,2}$, Noa Mazurski ${ }^{1,2}$, Atzmon Vakahi², \\ Sergei Remennik ${ }^{2}$, Inna Popov ${ }^{2}$, Anders Kristensen ${ }^{3}$ and Uriel Levy ${ }^{1,2}$ \\ ${ }^{\prime}$ Department of Applied Physics, The faculty of Science, The Hebrew University of Jerusalem, Jerusalem, 91904, Israel \\ ${ }^{2}$ The Center for Nanoscience and Nanotechnology, The Hebrew University of Jerusalem, Jerusalem, 91904, Israel \\ ${ }^{3}$ Department of Micro- and Nanotechnology, Technical University of Denmark, DK-2800 Kongens Lyngby, Denmark
}

\begin{abstract}
The absorption in amorphous silicon nano antennas is engineered for the purpose of post process structural change via resonant laser printing by illumination, thus shifting transmission and reflection spectrum in a controlled manner. (C) 2019 The Author(s) OCIS codes: (160.3918) Metamaterials; resonant laser printing
\end{abstract}

\section{Introduction}

Thin layered meta-materials, or meta-surfaces are relatively simple to fabricate using traditional Nanolithography techniques and may even be mass produced, yet the fabrication is confined to clean rooms and requires several complex steps and advanced equipment. Should Meta-Surface fabrication technology arrive at a point of mass availability - no more difficult to operate than a desk printer - the implications would be drastic, as it would be possible to prototype thin film elements on demand at an extremely low cost, tailored to the exact need of the researcher [1,2]. In this work, we attempt to address the question of metasurface tunability via two physical processes: Oxidation and crystallization. Crystallization does not change the size of the antenna drastically- however it does affect the effective refractive index of the array in a binary manner. Oxidation results in volume changes for the $\mathrm{Si}$ and thus shifts the Mie scattering of the antenna continuously by controlling the laser power and illumination time.

\section{Methodology}

First an array of Si antennas on glass is designed and fabricated to have an absorption resonance at the same wavelength of the incident beam. This array can be mass produced and should be thought of as "Blank paper" on which we will later print at a different location. A $532 \mathrm{~nm} \mathrm{CW}$ laser is attenuated by two rotating polarizers and focused onto the surface of the device which causes localized heating of the array. Depending on the energy density and illumination time, three separate regimes can be targeted. The first is high power and long exposure times, which gives rise to thermal ablation as seen in Fig. 1(a). The second is low power and short exposure times, which gives rise to crystallization of the amorphous silicon and requiring an activation energy of $470 \mathrm{~kJ} / \mathrm{mol}$ for nucleation as shown in Fig. 1(b). The third regime spans between the previous two and results in various sized changes to the antenna structure shown in Fig. 1(c).

(a)

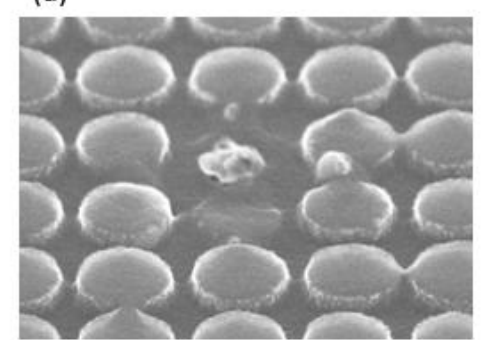

(b)

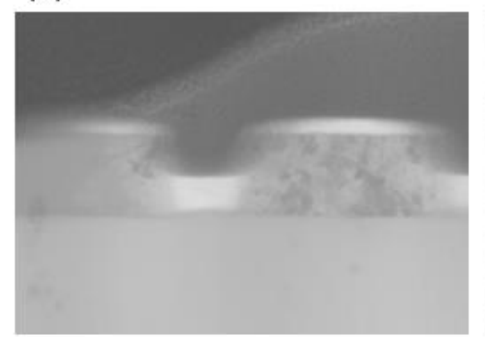

(c)

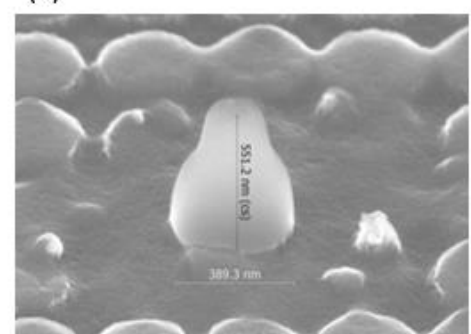

Fig.1. (a) SEM image of antenna ablation; Si antennas are coated with Espacer-300- a conducting polymer- to reduce charging (b) TEM cross section showing the transition from amorphous (left) to poly-Si (right) at the tail of the illuminating beam; various additional coatings are visible which were applied to generate the TEM sample (c) SEM image of drastic structural change to antenna dimensions.

The array is mounted on a motorized stage which in conjunction with an electrical shutter allows for patterning of spots Fig.2 (a), gratings Fig.2 (b) or any other design Fig.2 (c) - limited only by the motor resolution. 
(a)

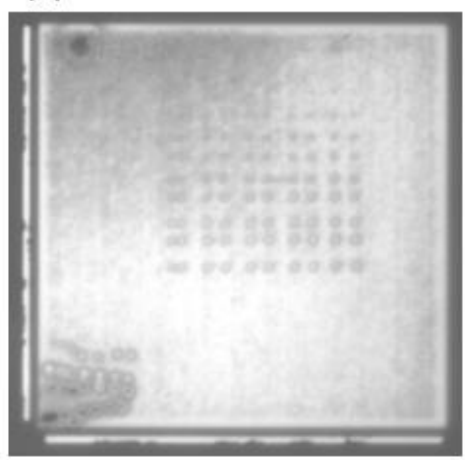

(b)

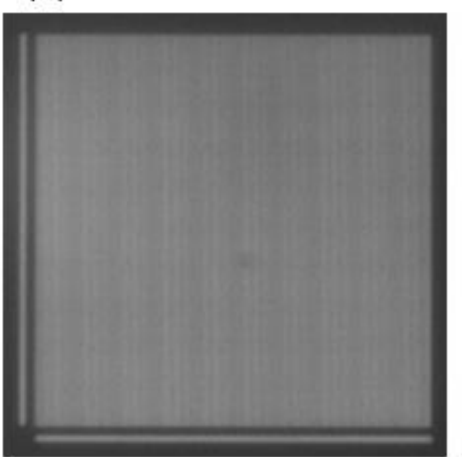

(c)

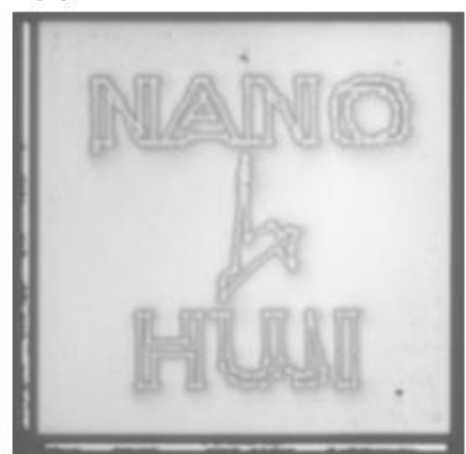

Fig.2. (a) Transmission imaging of 10x10 spot matrix varying laser power vs. Illumination time (b) Transmission imaging of crystallization grating with period of $2.3 \mathrm{um} \mathrm{(c)} \mathrm{Transmission} \mathrm{imaging} \mathrm{of} \mathrm{crystallization} \mathrm{patterning.} \mathrm{Array} \mathrm{size} \mathrm{in} \mathrm{all} \mathrm{cases} \mathrm{is}$ $100 \times 100 \mathrm{um}$, while the antenna period is $363 \mathrm{~nm}$ - bellow imaging resolution for this setup.

\section{Results}

A TEM sample has been fabricated and analyzed. It contains a reference area which has not undergone any illumination, a spot of low power showing crystallization only, and a spot of high power showing oxidation and structural change. Oxide thickness changes from $3.1 \mathrm{~nm}$ in the reference sample to $3.5 \mathrm{~nm}$ in the crystallization sample which is within the error in the TEM measurement due to a tilt between both samples. Fig.3 (a) shows qualitatively various structural changes corresponding to different laser power and illumination time. We were able to generate pillars 4 times the height of the original antenna with illumination times of seconds, indicating a rapid growth mechanism. In Fig.3 (b-d) spectroscopic data from a TEM measurement is shown. The top part of the structure lacks Oxygen while the bottom part shows a $30 \%$ increase in atomic weight of Oxygen and a lack of $\mathrm{Al}$ - which is present in the glass substrate - indicating oxidation of the base of the Si antenna being driven from the bottom upwards. Surrounding the entire structure is a $\mathrm{SiO} 2$ crust with an increased thickness of $25 \mathrm{~nm}$, indicating increased oxygen diffusion at the top of the antenna as well.

At high laser intensities and long exposure time (Fig.1 (c)) a ring of ablated material surrounds the pillar, caused by prolonged exposure to the tail of the Gaussian beam - with not enough energy to undergo the pillar formation process. The pillar itself is formed rapidly - on a time scale of dozens of nanoseconds according to heat simulations - exiting resonance with the laser and thus escaping the ablation process. While this growth mechanism is reminiscent of Vapor-Solid-Solid Nano-wire formation, additional inquiry should be performed to rule out melting and reshaping mechanisms.

(a)

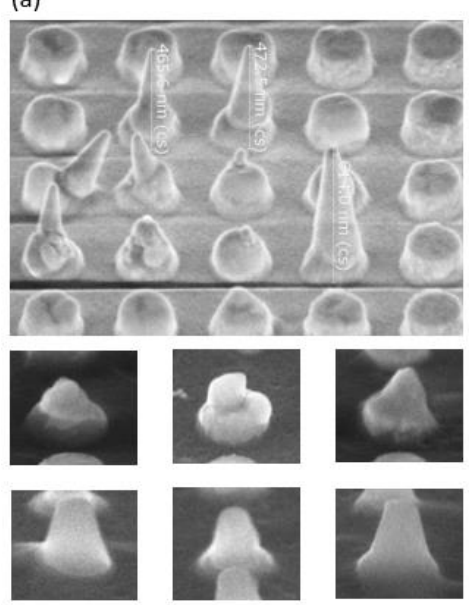

(b)

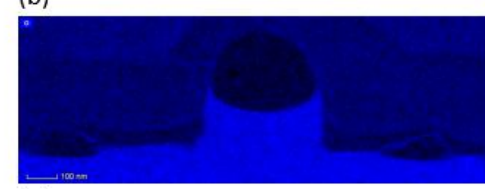

(c)

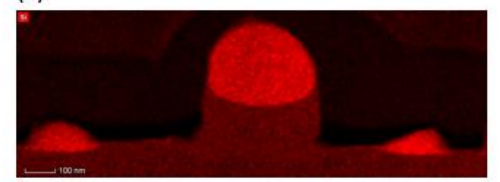

(d)

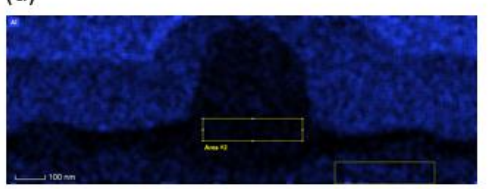

(e)

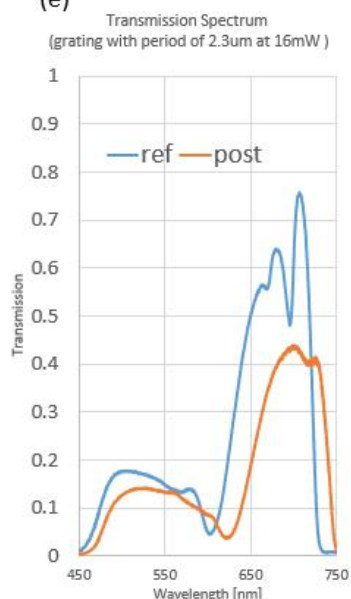

Fig.3. (a) SEM images showing various stages of the pillar growth process (b) TEM Oxygen distribution (c) TEM Silicon distribution (d) TEM Aluminum distribution (e) Transmission spectrum showing red shift due to a decreasing real part of the refractive index and increase in the imaginary part.

\section{References}

[1] X. Zhu, W. Yan, U. Levy, N. A. Mortensen and A. Kristensen, Science Advances 3, no. 5, e1602487 (2017).

[2] X. Zhu, C. Vannahme, E. H. Nielsen, N. A. Mortensen and A. Kristensen, Nature. Nanotechnol. 11, 325-329 (2016). 